\title{
High Frequency Variation of Colony Morphology and Chromosome Reorganization in the Pathogenic Yeast Candida albicans
}

\author{
By TAKAHITO SUZUKI, ${ }^{*}$ ISSEI KOBAYASHI, TOSHIO KANBE AND \\ KENJI TANAKA \\ Laboratory of Medical Mycology, Nagoya University School of Medicine, 65 Tsurumai, \\ Showa-ku, Nagoya 466, Japan
}

(Received 27 May 1988; revised 19 July 1988; accepted 12 September 1988)

\begin{abstract}
A clinical isolate of the pathogenic yeast Candida albicans varied in its colony morphology from smooth (o-smooth) to semi-rough type (SRT) and concomitantly lost its virulence for mice. In terms of DNA content, the smooth parent was near triploid when Saccharomyces cerevisiae strains of known ploidy were used as references. The SRT variant showed several features characteristic of polyploidy. From the SRT variant, revertant-like smooth (r-smooth) variants with recovered virulence were derived at a frequency of $5 \times 10^{-3}$. The results of pulsed-field gel electrophoresis on chromosomal DNA showed changes in patterns of chromosome-sized DNA bands in the SRT variant as well as in r-smooth variants, which correlated with these variations. Correlations between colony morphology, state of ploidy and virulence of this asporogenous yeast are considered.
\end{abstract}

\section{INTRODUCTION}

Genetic switch processes with gene rearrangement have been found to alter expression of cell surface constituents in unicellular micro-organisms, including phase variation of bacterial flagella (lino \& Kutsukake, 1983; Simon et al., 1980), antigenic variation in a relapsing fever Borrelia (Meier et al., 1985), pilus expression in Neisseria (Meyer et al., 1982) and trypanosome antigenic variation (Borst \& Cross, 1982). In the dimorphic, pathogenic yeast Candida albicans, high-frequency switching of colony morphology has been examined, in which this asexual yeast switches heritably at a frequency of $10^{-2}$ to $10^{-4}$ between at least seven colony-morphology phenotypes (Slutsky et al., 1985) or between white and opaque ones (Slutsky et al., 1987). However, because systems for genetic analysis are limited in this yeast, no clear mechanism has been deduced for these switching phenomena.

Although many $C$. albicans strains are diploid (Whelan \& Magee, 1981), we recently discovered the phenomenon of ploidy shift in a strain with polyploidy consisting of at least two different states of ploidy, diploid (or near diploid) and tetraploid (or near tetraploid): diploid cells in a population of the strain enter G2-delay and then bypass the M-phase, resulting in a shiftup of ploidy state; tetraploid cells engage in reductional nuclear division during shiftdown of ploidy state, producing diploid daughter cells. During the process of shiftdown, multiple spindles can be observed by electron microscopy, resembling meiosis II of sporulation in Saccharomyces cerevisiae (Suzuki et al., 1986b). However, no functional significance of this ploidy shift in C. albicans was apparent. Here, we investigate the high-frequency variation (or switching) of colony morphology between smooth and semi-rough types, and the correlation of this variation with pathogenicity.

† Present address: Biological Laboratory, Faculty of Science, Nara Women's University, Nara 630, Japan.

Abbreviations: IW, irregular wrinkle; SRT, semi-rough type; DABA, diaminobenzoic acid; DAPI, 4',6diamidino-2-phenylindole; FITC, fluorescein isothiocyanate; PFGE, pulsed-field gel electrophoresis. 


\section{METHODS}

Organisms, media and growth conditions. A strain of C. albicans (NUM961) was isolated from a patient at Nagoya University Hospital; it was of serotype A (determined by using Candida Check Serum supplied by Iatron Laboratories, Tokyo, Japan), and showed production of both germ tubes and chlamydospores when tested according to McGinnis (1980). S. cerevisiae strains X2180-1A (MATa), X2180-1B (MAT $\alpha)$ and X2180-2D (MATa $)$ were kindly given to us by Dr Ohya, Tokyo University, and used as standards for DNA content and chromosome banding patterns. An authentic $C$. albicans strain, STN57, a derivative of CBS5736 (Suzuki et al., $1986 a$ ), was also used as a standard. Yeast cells were grown in YPD medium [containing, per litre, $10 \mathrm{~g}$ Bactopeptone (Difco), $10 \mathrm{~g}$ yeast extract and $20 \mathrm{~g}$ glucose] with shaking (120 strokes $\mathrm{min}^{-1}$ ) at either 30 or $37^{\circ} \mathrm{C}$ as described below. For solid medium, $2 \%(\mathrm{w} / \mathrm{v})$ agar was added to YPD medium. In order to isolate colonymorphology variants from the parent, yeast cells grown on YPD plates were suspended in sterile $0.5 \% \mathrm{NaCl}$, plated onto YPD plates after appropriate dilutions and incubated at either one of the two temperatures. For examination of virulence for mice, cells were incubated in YCB-AS broth (Shimidzu et al., 1987), composed of $11.7 \mathrm{~g}$ Yeast Carbon Base (Difco) and $5.0 \mathrm{~g}$ ammonium sulphate per litre of distilled water.

DNA determination. DNA content per cell was determined using diaminobenzoic acid (DABA) by the method of Hesse et al. (1975). Calf thymus DNA (Sigma) was used as reference.

Fluorescent-microscope photometry. Yeast cells were harvested from YPD media, fixed in 50\% (v/v) ethanol, stained with propidium iodide $\left(10 \mu \mathrm{g} \mathrm{ml}^{-1}\right)$ in the presence of RNAase $A\left(1 \mathrm{mg} \mathrm{ml}^{-1}\right)$ and examined by fluorescent-microscope photometry as described previously (Suzuki et al., 1986b). A Zeiss MPM03FL photometer was used and the nuclear DNA fluorescence of individual cells was determined by measuring a random sample of 200 to 400 cells from a given culture.

Visualization of nuclear spindles by fluorescence microscopy. Exponentially growing yeast cells in YPD media were fixed with $3 \%(\mathrm{w} / \mathrm{v})$ paraformaldehyde and stained with monoclonal antitubulin YOL1/24 (Sera-Lab), plus fluorescein isothiocyanate (FITC)-anti-rat IgG as described by Kilmartin \& Adams (1984). Slides were mounted in $p$-phenylenediamine $/ 90 \%(\mathrm{w} / \mathrm{v})$ glycerol containing 4',6-diamidino-2-phenylindole (DAPI, $0.05 \mu \mathrm{g} \mathrm{ml}^{-1}$ ). For phase-contrast-DAPI fluorescence, an Olympus UVFL 100PL objective was used with a combination of UG1, DM400 and L435 filters. For FITC fluorescence, a UVFL 100 objective was used with a combination of BP490, EY455, BM500 and O515 filters.

Virulence test. Cells cultured on YCA-AS broth were collected by centrifugation, washed twice and resuspended in saline $(0.85 \% \mathrm{NaCl})$. Dilutions of the cell suspension were made for inocula by counting the cells with a haemocytometer. Viable cells of each strain were 85 to $95 \%$ of the total cells as determined by plate counting. Male general-purpose albino Swiss mice (ICR strain), 5 to 7-weeks-old, were used. Mice were injected via the lateral tail vein with $10^{7}, 10^{6}$ or $10^{5}$ cells of each inoculum and observed for up to $50 \mathrm{~d}$ after infection.

Examination of proteinase secretion. The plate biochemical test described by Odds \& Abbott (1980) was used to examine proteinase production by individual strains. Basal medium no. 2 was prepared according to their method; bovine serum albumin (BSA; fraction V, Sigma) was added, and the medium was then filter-sterilized and plated by adding agar (Noble agar, Difco). The final concentration of BSA was $0 \cdot 1 \%$.

Pulsed-field gel electrophoresis (PFGE). Sample preparation for PFGE was according to Carle \& Olson (1984) and Magee \& Magee (1987). After several trials, we decided to use either a 2.5 min pulse time for a 18 to $24 \mathrm{~h}$ run to obtain good resolution of DNA sized around $1000 \mathrm{kbp}$ or a $5 \mathrm{~min}$ pulse time for a 45 to $48 \mathrm{~h}$ run to resolve the higher molecular-size DNA bands. A $0.8 \%$ agarose (Wako Chemicals) gel $(20 \times 20 \mathrm{~cm})$ was prepared. The angle formed at the sample loading wells between the two alternative fields was adjusted to $120^{\circ}$. The Pulsaphor system (Pharmacia-LKB) was used with a constant voltage of $300 \mathrm{~V}$ and with the temperature maintained at $10^{\circ} \mathrm{C}$.

\section{RESULTS}

\section{Spontaneous semi-rough variants derived from the smooth parent NUM961}

Strain NUM961 had a smooth colony morphology on YPD plates and cells removed from the surface of such a smooth colony all had the spherical yeast form (Fig. 1a). As smooth colonies grown at both 30 and $37^{\circ} \mathrm{C}$ had an unwrinkled surface, with no aerial mycelia, we will refer to the original parent strain as 'o-smooth' according to the description by Slutsky et al. (1985). When large numbers of cells of o-smooth were plated as colonies on YPD plates, a semi-rough variant colony appeared spontaneously at a frequency of $3 \times 10^{-5}$. Semi-rough colonies of this variant had a rough surface in the central portion of a colony with an apparently smooth periphery. When an original isolate of this semi-rough variant morphology was plated as colonies, the variant phenotype persisted in more than $99 \%$ of the offspring in successive clonal platings. We will refer to this semi-rough type as 'SRT'. The SRT did not appear to fit any of the descriptions of Slutsky et al. $(1985,1987)$ but rather seemed to share several features in common 

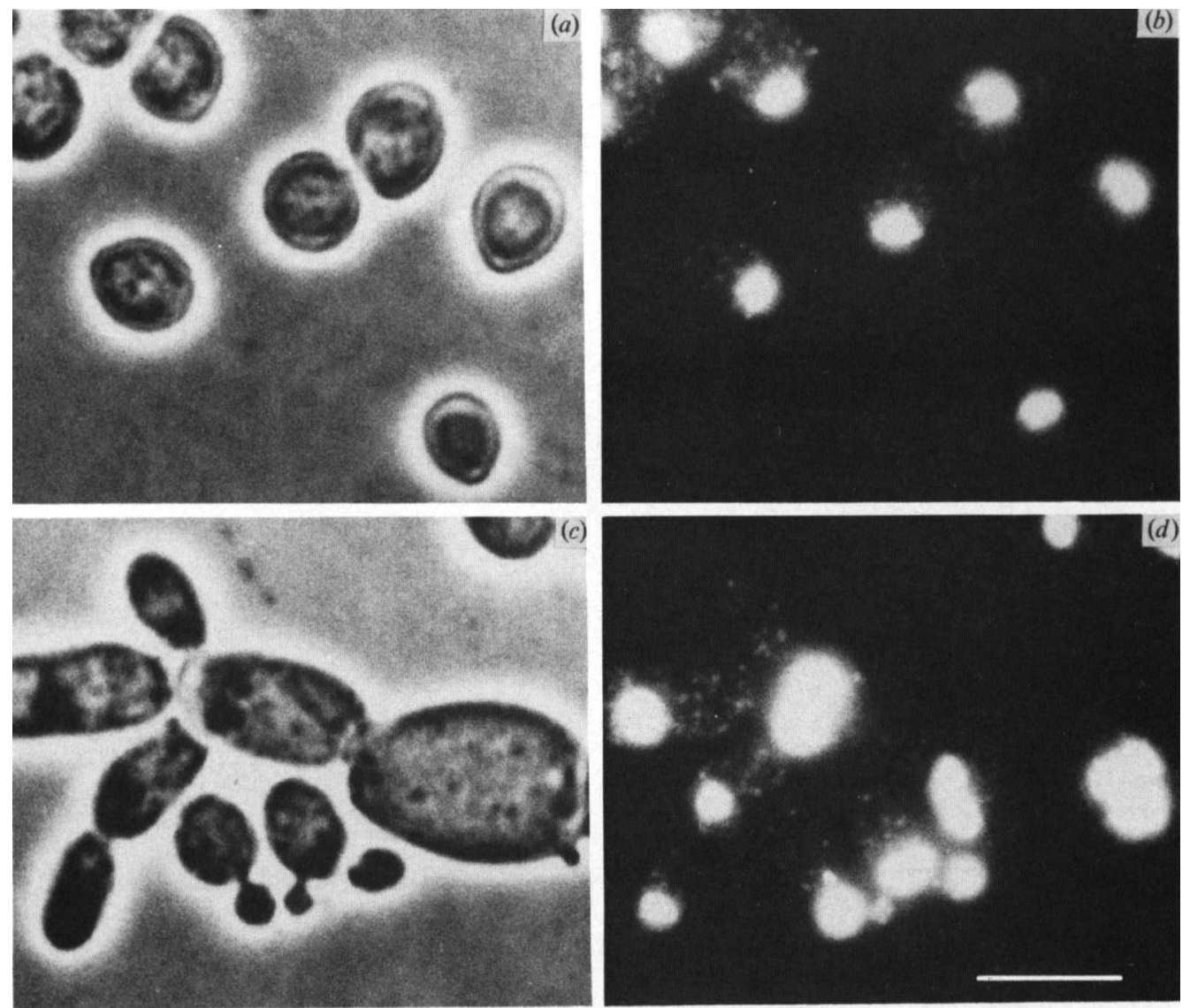

Fig. 1. Morphological differences between the o-smooth parent and the SRT1 variant of $C$. albicans NUM961 as shown by phase-contrast $(a, c)$ and fluorescent microscopy $(b, d)$. Cells were stained with propidium iodide. $(a, b)$, Cells from a mature smooth colony of the o-smooth parent grown on YPD agar; $(c, d)$, cells from a mature SRT1 colony. An Olympus BH2-RFK was used with combination of BP545, DM580 and O590 filters. Bar, $10 \mu \mathrm{m}$.

with the colony types classified as 'A' by Brown-Thomsen (1968). Characteristics of the SRT colony morphology became more distinct when the variant cells were cultured at $37^{\circ} \mathrm{C}$ rather than at $30^{\circ} \mathrm{C}$ or lower temperatures. No difference was detected in the antigenic determinants of the cells of SRT colonies compared to o-smooth cells using commercial Candida Check Serum. In contrast to o-smooth cells, those removed from the surface of SRT colonies consisted of both budding yeasts and pseudohyphal cells (Fig. 1c). The size of yeast cells of SRT colonies was heterogeneous: small cells, 3 to $4 \mu \mathrm{m}$ long, similar to those of o-smooth; and large cells, ovoid, pyriform or clavate in shape. The large cells were 3.5 to $7 \mu \mathrm{m}$ wide and 4 to $20 \mu \mathrm{m}$ long. These different-sized cells of the SRT variant seemed to us to be in a different ploidy state, as described previously (Suzuki et al., 1986b). In addition to the SRT colonies, irregular-wrinkle (IW) colonies appeared spontaneously at a frequency of $1 \times 10^{-4}$. These IW colonies were different from the SRT in that the whole of an IW colony had a wrinkled surface. One representative spontaneous SRT variant, designated SRT1, was characterized further.

\section{DNA content and chromosomal banding pattern of SRTI}

In order to examine the ploidy of this variant, DNA content determinations were done on both the o-smooth parent and SRT1 as well as IW variants (Table 1). The mean total DNA content per cell was $52.8 \pm 0.6 \mathrm{fg}$ in the o-smooth parent, $76.0 \pm 5.1 \mathrm{fg}$ in the SRT1 and 

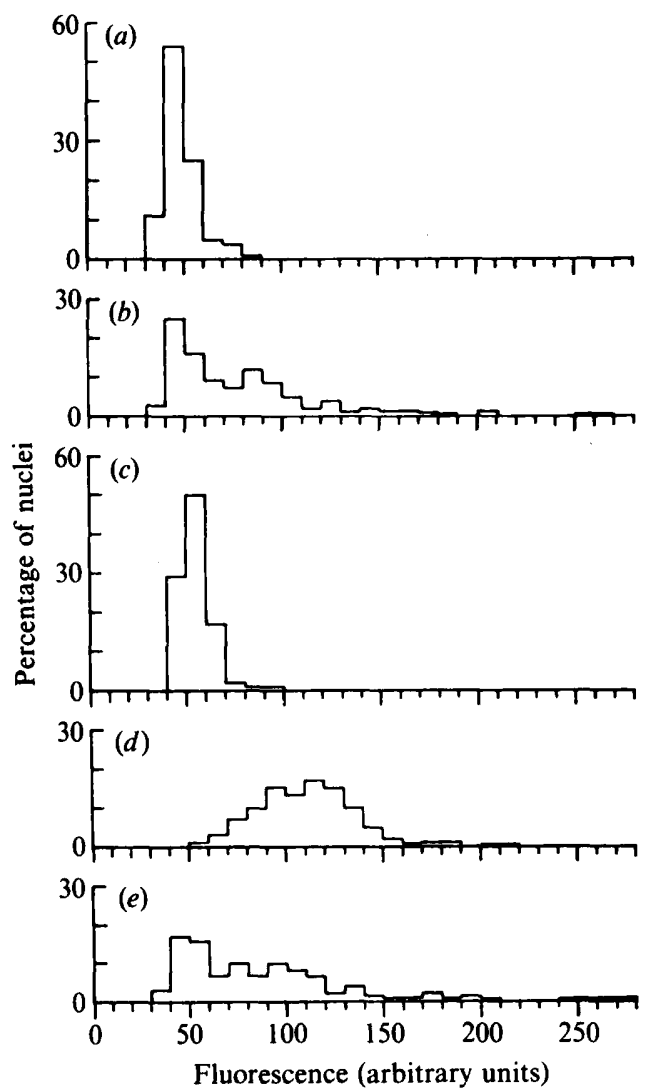

Fig. 2. Histograms comparing nuclear DNA content of the o-smooth parent (a), SRT1 (b), RSK10 (a representative RSK variant similar to o-smooth) $(c)$, RSK20 $(d)$ and RSK 18 (a polyploid RSK variant) $(e)$. Cells were grown to stationary phase in YPD and stained with propidium iodide. Fluorescence intensity of nuclear DNA was measured using a Zeiss fluorescent microscope-photometer MPM03. In each experiment, data were obtained from more than 200 nuclei.

$53.4 \pm 0.5 \mathrm{fg}$ in an IW variant. The o-smooth parent thus had a much higher DNA content than the authentic $C$. albicans strain STN57 (39.2 $\pm 1.6 \mathrm{fg})$ and many other strains of this organism which have a DNA content close to that of $S$. cerevisiae diploid strains (Riggsby et al., 1982). Also, the SRT1 variant had approximately one and a half times the DNA content of its parent. Fluorescent microscopic observations showed that cells of the o-smooth parent and those of the IW variant had a nucleus and that small cells of SRT1 variant had one nucleus but large yeast cells of the same SRT1 strain had either one large nucleus or more than two (up to eight) nuclei. Fig. 2 shows the wider distribution of DNA content in the SRT1 variant. Attempts were made to visualize the nuclear spindles of both strains, by using anti-yeast-tubulin antibodies. Small mitotic yeast cells of SRT1 had either one thicker spindle or two spindles (Fig. 3b,c). Cells from the IW variant showed similar features to the o-smooth parent. Hence, we refer to the nature of ploidy of SRT1 as 'polyploidy.'

The technique of PFGE has allowed the visualization of S. cerevisiae chromosomes (Carle \& Olson, 1985; Schwartz \& Cantor, 1982) as well as those of C. albicans (Magee \& Magee, 1987). Using this technique we observed at least 10 bands in the o-smooth parent and two additional bands in SRT1 (Fig. 4, lanes 2 and 3). Five were common to the o-smooth parent, SRT1 and STN57 (Fig. 4, lanes 21 and 22). On the other hand, no difference was detected between the banding patterns of the o-smooth parent and the IW variant (data not shown). 
(a)
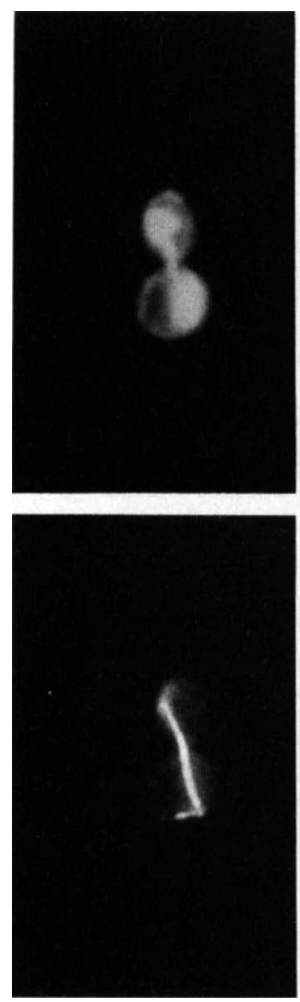

(b)
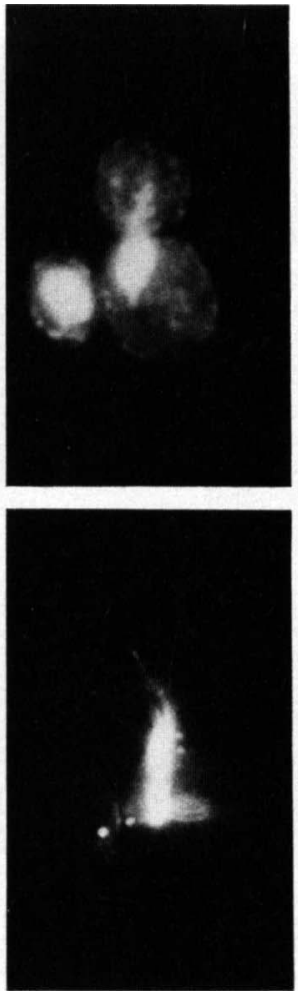

(c)
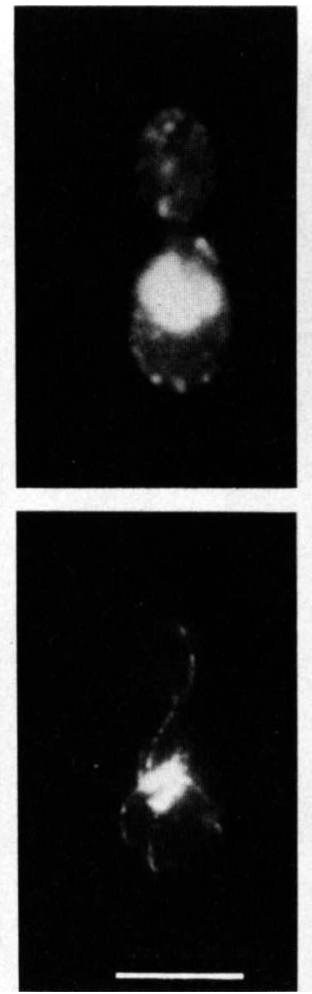

$(d)$
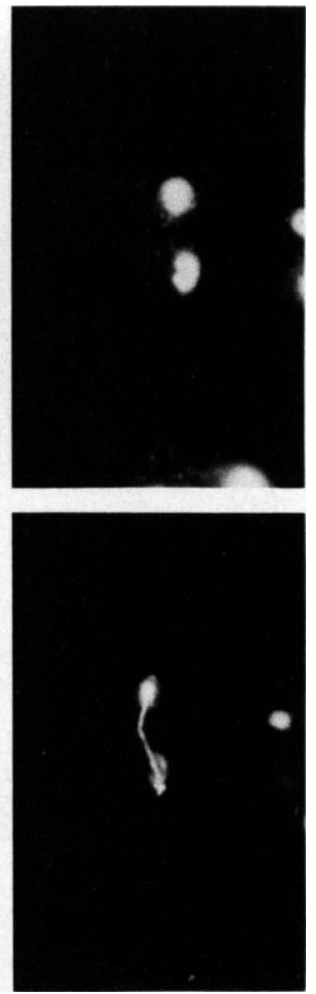

Fig. 3. Fluorescent micrographs of polyploid SRT1 cells double-labelled for DNA (DAPI-fluorescence, top) and tubulin (FITC-fluorescence, bottom). A mitotic small cell with a thin spindle (a), a mitotic large cell with a thick spindle $(b)$, and a mitotic large cell with two spindles $(c)$ of SRT1 and the o-smooth parent $(d)$. Bar, $10 \mu \mathrm{m}$.

\section{Loss of virulence of the SRT variant}

Another interesting finding was the loss of virulence of SRT1 for mice. Even when $10^{7}$ cells of SRT1 (more than ten times the dosage level generally used for virulence tests) were intravenously inoculated into the caudal vein of mice, no lethal effect was observed even after $\mathbf{4 0}$ to $50 \mathrm{~d}$, whereas the same dosage of the o-smooth parent variant killed all mice tested within 2 weeks (Table 2). (The IW variant also killed all mice tested within 2 weeks: data not shown.) Secretion of acid proteinase, which has been considered to be a virulence factor of $C$. albicans (MacDonald \& Odds, 1983; Kwon-Chung et al., 1985), was detected in the o-smooth parent and the SRT1 variant as well as in the IW variant. Therefore, loss of virulence in the SRT1 variant may be due to a deficiency of some unknown virulence factor(s) other than the production and secretion of proteinase.

\section{High-frequency variation of colony morphology of the SRT1 variant}

When cells of SRT1 were plated as clones on VPD plates, apparently smooth colony morphology appeared at a high frequency $\left(5 \times 10^{-3}\right)$. We will refer to this revertant morphology as 'r-smooth'; the r-smooth variant isolated here was designated RSK. Sixteen RSK variants were obtained spontaneously (RSK5 to RSK20). DNA determinations and virulence tests were done on each of the variants (Tables 1 and 2). The mean DNA content of RSK20 was twice that of the o-smooth strain (total DNA content $110.5 \pm 13.6 \mathrm{fg}$ per cell). The other RSK variants had a DNA content 0.6 to 1.3 times that of their o-smooth grandparent. However, all these RSK variants had more DNA than the diploid $S$. cerevisiae strain X2180-2D. In all RSK variants, polyploid large yeast cells were found as either a very minor fraction (12 RSK variants, 
(a)

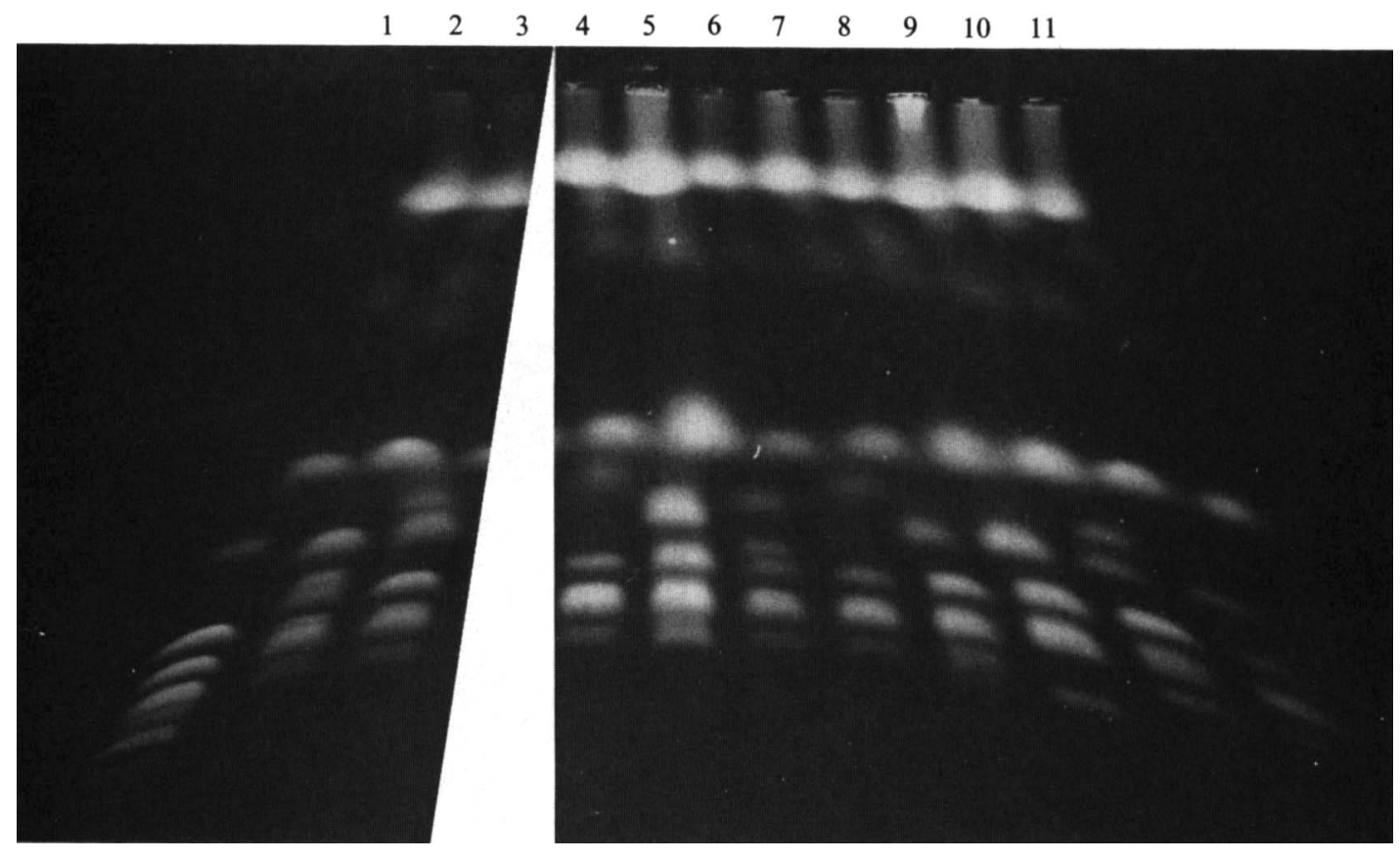

(b)

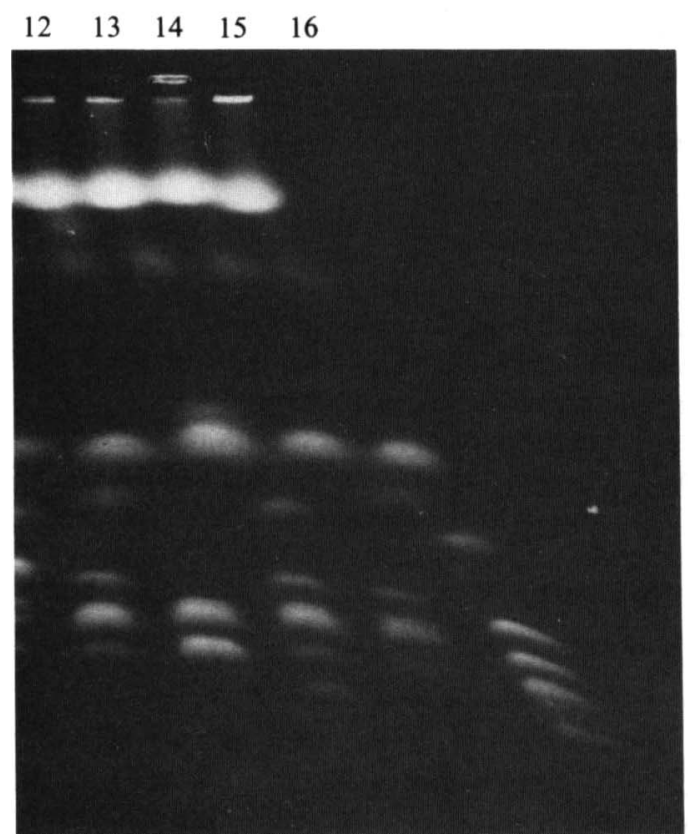

(c)

(d)

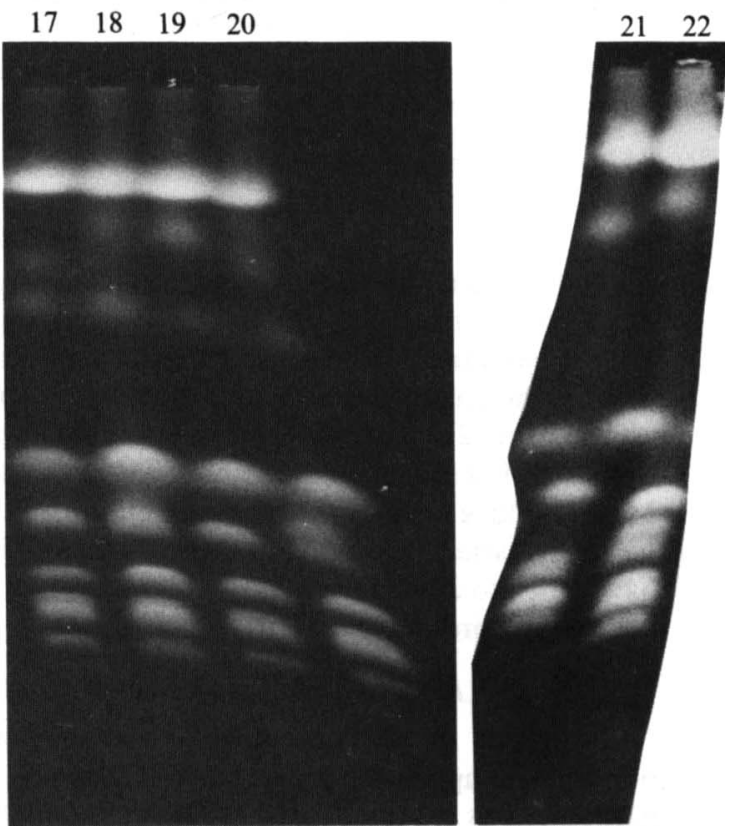

Fig. 4. (a) PFGE banding patterns of chromosomal DNA in a variants of C. albicans NUM961. A $0.8 \%$ agarose gel $(20 \times 20 \mathrm{~cm})$ was run at a $5 \mathrm{~min}$ pulse rate at $10 \mathrm{~V} \mathrm{~cm}^{-1}$ for $45 \mathrm{~h}$. Gels were stained with ethidium bromide $\left(1 \mu \mathrm{g} \mathrm{ml}^{-1}\right)$ for $30 \mathrm{~min}$. Lane 1, S. cerevisiae X2180-2D (diploid); lane 2, C. albicans NUM961 o-smooth parent; lane 3, semi-rough SRT1 variant; lanes 4 to 11, revertant smooth variants RSK5 to RSK20, respectively. (b) RSK13 to RSK 16 (lanes 12 to 15 , respectively) and $S$. cerevisiae X2180-2D (lane 16) in a different run (conditions as above). (c) RSK17 to RSK20 (lanes 17 to 20, respectively) in a different run (conditions as above). (d) C. albicans STN57 (lane 21) and NUM961 osmooth parent (lane 22) in a different run (conditions as above). 
Table 1. Mean DNA content and ploidy state of the o-smooth parent NUM961, SRT1 and r-smooth RSK variants

\begin{tabular}{|c|c|c|c|c|}
\hline \multirow[b]{2}{*}{ Strain } & \multirow[b]{2}{*}{ DNA (fg per cell)* } & \multicolumn{2}{|c|}{ Relative ploidy $\dagger$} & \multirow{2}{*}{$\begin{array}{c}\text { Presence of } \\
\text { polyploid cells }\end{array}$} \\
\hline & & A & $\overrightarrow{\text { B }}$ & \\
\hline o-smooth & $52.8 \pm 0.6$ & 3.0 & 1.0 & - \\
\hline SRT1 & $76 \cdot 0 \pm 5 \cdot 1$ & $4 \cdot 3$ & 1.4 & ++ \\
\hline RSK 5 & $45 \cdot 6 \pm 1 \cdot 7$ & $2 \cdot 6$ & 0.9 & + \\
\hline RSK6 & $44.5 \pm 0.3$ & 2.5 & 0.8 & + \\
\hline RSK 7 & $42 \cdot 1 \pm 3.8$ & $2 \cdot 4$ & 0.8 & + \\
\hline RSK8 & $46.5 \pm 1.0$ & $2 \cdot 6$ & 0.9 & + \\
\hline RSK9 & $48.3 \pm 1.8$ & 2.7 & 0.9 & + \\
\hline RSK10 & $53.7 \pm 1.3$ & $3 \cdot 1$ & 1.0 & + \\
\hline RSK11 & $49 \cdot 6 \pm 2.0$ & 2.8 & 0.9 & + \\
\hline RSK12 & $40 \cdot 1 \pm 2 \cdot 1$ & $2 \cdot 3$ & 0.8 & + \\
\hline RSK 13 & $62.0 \pm 5.4$ & 3.5 & 1.2 & ++ \\
\hline RSK14 & $32 \cdot 0 \pm 2 \cdot 0$ & 1.8 & 0.6 & ++ \\
\hline RSK 15 & $48 \cdot 6 \pm 4 \cdot 0$ & 2.8 & 0.9 & + \\
\hline RSK 16 & $57 \cdot 6 \pm 4 \cdot 2$ & $3 \cdot 3$ & $1 \cdot 1$ & + \\
\hline RSK17 & $37.4 \pm 0.6$ & $2 \cdot 1$ & 0.7 & ++ \\
\hline RSK 18 & $70 \cdot 1 \pm 4 \cdot 1$ & $4 \cdot 0$ & 1.3 & ++ \\
\hline RSK 19 & $49 \cdot 6 \pm 0.3$ & $2 \cdot 8$ & 0.9 & + \\
\hline RSK20 & $110.5 \pm 13.6$ & 6.3 & $2 \cdot 1$ & + \\
\hline $\mathrm{X} 2180-1 \mathrm{~A}$ & $17.6 \pm 1.5$ & $1 \cdot 0$ & 0.3 & - \\
\hline $\mathrm{X} 2180-2 \mathrm{D}$ & $36.5 \pm 1.8$ & $2 \cdot 1$ & 0.7 & - \\
\hline STN57 & $39 \cdot 2 \pm 1 \cdot 6$ & $2 \cdot 2$ & 0.7 & - \\
\hline
\end{tabular}

* Determined using DABA.

$\dagger$ Relative ploidy was detemined after normalization of the haploid S. cerevisiae X2180-1A (A) or of the osmooth C. albicans parent (B).

$¥$ Cell of exponential-phase cultures of each strain were examined by fluorescent-microscope photometry. -, Percentage of polyploid cells (which includes multinucleate cells) less than $0.1 \% ;+$, percentage $0.1 \%-5 \% ;++$, percentage more than $5 \%$.

Table 2. Virulence test for mice of the o-smooth parent, semi-rough SRT1 and r-smooth RSK variants

$\begin{array}{lccc}\text { Strain } & \begin{array}{c}\text { Mortality } \\ \text { after 40 d }\end{array} & \begin{array}{c}\text { Mortality } \\ \text { rate (\%) }\end{array} & \begin{array}{c}\text { Median death } \\ \text { time (d) }\end{array} \\ \text { O-smooth } & 20 / 20 & 100 & 3 \\ \text { SRT1 } & 0 / 20 & 0 & - \\ \text { RSK5 } & 3 / 10 & 30 & 9 \\ \text { RSK6 } & 5 / 10 & 50 & 7 \\ \text { RSK7 } & 3 / 10 & 30 & 16 \\ \text { RSK8 } & 4 / 10 & 40 & 15 \\ \text { RSK9 } & 4 / 5 & 80 & 17 \\ \text { RSK10 } & 6 / 10 & 60 & 27 \\ \text { RSK11 } & 6 / 10 & 60 & 24 \\ \text { RSK12 } & 8 / 10 & 80 & 10 \\ \text { RSK13 } & 4 / 5 & 80 & 19 \\ \text { RSK14 } & 8 / 10 & 80 & 14 \\ \text { RSK15 } & 2 / 5 & 40 & 15 \\ \text { RSK16 } & 3 / 5 & 60 & 14 \\ \text { RSK17 } & 4 / 5 & 80 & 23 \\ \text { RSK18 } & 1 / 5 & 20 & 16 \\ \text { RSK19 } & 4 / 5 & 80 & 17 \\ \text { RSK20 } & 3 / 5 & 60 & 23\end{array}$

indicated as + in Table 1) or a few percent or more of their population (four RSK variants, indicated ++ in the Table). In RSK13 and RSK18, ploidy state and DNA content remained similar to that of their parent SRT1, but in the other RSK variants, DNA content showed variation. Only in the four r-smooth variants RSK9, RSK10, RSK11 and RSK16 had the DNA 
content returned to the level found in their o-smooth grandparent. This seemed to us to suggest the occurence of ploidy-shift (in the case of RSK20) or transition to an aneuploid state (in most other cases). Any direct correlation between the type of colony morphology and ploidy state or between ploidy state and virulence (Tables 1 and 2) in these RSK variants was difficult to find. However, recovery of virulence was correlated with the colony transition from semi-rough to $\mathrm{r}$-smooth. These reversion phenotypes, especially found on variation of ploidy states among r-smooth variants, suggested that the r-smooth variation was not so much a true reversion but a second site reversion. PFGE banding patterns of the RSK variants were different from each other. Various numbers of bands, from 9 to 14, were detected. However, at least 5 common bands were observed among the o-smooth parent, SRT1 and RSK variants as well as STN57 (Fig. 4). This indicated that the variation from semi-rough to r-smooth was not simply due to a reversion process but was to some event accompanied by chromosome reorganization. No direct correlation was found between either a particular PFGE banding pattern and virulence or between the number of bands and ploidy state (11 bands in RSK20, which had the highest DNA content, and 14 bands in RSK6, which had a DNA content less than its o-smooth grandparent). There appeared to be no specific correlation between banding pattern and virulence.

\section{DISCUSSION}

C. albicans is an opportunistic pathogen and the high-frequency variation of virulence described here appears to be a potential model system for use in the study of its pathogenicity. From our work, one can assume the existence of virulence factor(s) other than acid proteinase in this organism. The avirulence of SRT1 does not seem to be due to differences in growth rate nor in ability to produce acid proteinase compared to the o-smooth parent. It is also possible that SRT1 cells may produce factor(s) that repress activity of the proteinase in mice.

Electron microscopic observations on the fine structure of the cell wall of both strains revealed no distinct difference (unpublished data). In terms of the serotypes, both strains showed no difference. However, since the serotype examined here was a reflection of structure of the main polysaccharide chains in the yeast cell wall (Suzuki, 1981), differences in side-chains of the cell wall polysaccharides cannot be excluded. In the case of white-opaque colony variation in this organism (Slutsky et al., 1987), Anderson \& Soll (1987) found that a specific antigen discriminated between these two types of colony morphology. Further investigations on the differences between the o-smooth parent and SRT variants are in progress.

The polyploid nature of the SRT1 variant does not seem to relate directly to its loss of virulence because four polyploid strains (RSK13, 14, 17 and 18) were virulent for mice. More plausible is its relatedness to the high efficiency of variation. The frequency of variation of the SRT1 strain to r-smooth was several orders of magnitude greater than that of the o-smooth parent to SRT variants. Greater virulence of o-smooth may be correlated with less frequent variation to avirulent SRT variants.

It appears reasonable to assume that the chromosome reorganization described here is coupled to the process of ploidy shift. Cytological features of SRT1, i.e. that two or more spindles were formed in a nucleus as shown in Fig. 3, might be the structural basis for the phenomenon of high-frequency variation. Our unpublished data on the treatment of thiabendazole in the osmooth parent (this drug binds microtubles and inhibits microtubule-mediated cellular functions) indicated a hundred-fold increase in the frequency of occurrence of SRT variants; the fact that after treatment the culture accumulated cells with multiple spindles (unpublished data) also seems to support this idea.

In terms of DNA content, one cannot discriminate between the two possible cases simply from the data on mean DNA content per cell. For example, in the polyploid state in which there is only a limited fraction of polyploid cells there is a slightly higher DNA content than expected. The other case is in the aneuploid state in which the DNA content is near the diploid or triploid level and the presence of aneuploid chromosomes gives a slight increase in the DNA content. In our study, both of these cases appeared. The r-smooth RSK 20 strain had twice the DNA content of the o-smooth strain, which seemed to suggest that the process of ploidy-shift had occurred, 
whereas the other RSK variants appeared to be in the aneuploid state. In either case, dosage effects of some gene(s) may be correlated with the changes of phenotypes including colony morphology, virulence and ploidy-shift in these variations.

Examination of chromosome banding patterns indicated that the variation of both o-smooth to SRT and SRT to r-smooth were accompanied by addition and/or deletion of chromosomesized bands. Except for five common bands, the pattern of addition or deletion of bands depended on the strain. No correlation was found between individual bands and the observed phenotypes. Further investigations including Southern hybridization experiments are required to examine homology between and derivation of individual chromosomal bands. Our work strongly supports the view that $C$. albicans has polymorphisms in chromosome band-size as proposed by Magee \& Magee (1987), and suggests that the chromosome reorganization described here may play a role in producing such polymorphism in this asporogenous yeast.

In Drosophila, a substantial case can be made for the causal association of transposable elements and mutation, especially in the case of spontaneous mutation (Rubin, 1983). Recently, Scherer \& Stevens (1988) showed a dispersed, repeated DNA segment (or a gene family) isolated from $C$. albicans DNA. They also found high frequencies of DNA polymorphism among clinical isolates using this segment as a probe. The gene family was shown to have many of the features common to a variety of eukaryotic transposable elements. The chromosomal reorganization in our study has features from which one can infer the occurrence of unequal crossing-over (defined as production of a tandem duplication and a reciprocal deletion). In $S$. cerevisiae, the phenomenon of unequal crossing-over has been demonstrated to occur via the Tyl transposable element (Roeder, 1983). Therefore, further studies are needed to clarify whether such mobile elements participate in the production of polymorphisms of chromosome-sized DNA coupled with the phenomenon of high frequency variation described here.

This research was supported in part by Grant-in-aid for Scientific Research on Priority Areas (no. 62616504) from the Ministry of Education, Science and Culture, and a grant from the Ishida Foundation.

\section{REFERENCES}

Anderson, J. M. \& SOll, D. R. (1987). Unique phenotype of opaque cells in the white-opaque transition of Candida albicans. Journal of Bacteriology 169, 5579-5588.

Borst, P. \& Cross, S. A. M. (1982). Molecular basis for trypanosome antigenic variation. Cell 29, 291-303.

Brown-Thomsen, J. (1968). Variability in Candida albicans (Robin) Berkhout. I. Studies on morphology and biochemical activity. Hereditas 60, 355-398.

CARLE, G. F. \& OLSON, M. V. (1984). Separation of chromosomal DNA molecules from yeast by orthogonal-field-alternation gel electrophoresis. Nucleic Acids Research 12, 5647-5664.

Carle, G. F. \& Olson, M. V. (1985). An electrophoretic karyotype for yeast. Proceedings of the National Academy of Sciences of the United States of America 82, 3756-3760.

Hesse, G., Linder, R. \& KREBS, D. (1975). Schnelle fluorometrische desoxyribose-spezifische DNS-Bestimmung an nicht desintegrierten Mikroorganismen mit 3,5-Diaminobenzoesäure (DABA). I. Chemischanalytische Methodik und Anwendung auf Hefepopulationen. Zeitschrift für Allgemeine Mikrobiologie 15, 9-18.

Iino, T. \& KuTSuKaKe, K. (1983). Flagellar phase variation in Salmonella: a model system regulated by flip-flop DNA inversion. In Nucleic Acid Research: Future Developments, pp. 395-406. Edited by K. Mizobuchi, I. Watanabe \& J. D. Watson. New York: Academic Press.
Kilmartin, J. V. \& Adams, A. E. M. (1984). Structural rearrangements of tubulin and actin during the cell cycle of the yeast Saccharomyces. Journal of Cell Biology 98, 922-933.

Kwon-Chung, K. J., Lehman, D., Good, C. \& MAGEe, P. T. (1985). Genetic evidence for role of extracellular proteinase in virulence of Candida albicans. Infection and Immunity 49, 571-575.

MACDONALD, F. \& ODDS, F. C. (1983). Virulence for mice of a proteinase-secreting strain of Candida albicans and a proteinase-deficient mutant. Journal of General Microbiology 129, 431-438.

MCGinNIs, M. R. (1980). Laboratory Handbook of Medical Mycology. New York: Academic Press.

MAGEE, B. B. \& MAGEE, P. T. (1987). Electrophoretic karyotypes and chromosome numbers in Candida species. Journal of General Microbiology 133, 425430.

MeIER, J. T., Smon, M. I. \& BArbour, A. G. (1985). Antigenic variation associated with DNA rearrangements in a relapsing fever Borrelia. Cell 41, 403409.

Meyer, T. F., Mlawer, N. \& So, M. (1982). Pilus expression in Neisseria gonorrhoeae involves chromosomal rearrangement. Cell 30, 45-52.

ODDs, F. C. \& ABBOTT, A. B. (1980). A simple system for the presumptive identification of Candida albicans and differentiation of strains with the species. Sabouraudia 18, 301-317.

Riggsby, W. S., Torres-Bauza, L. J., Wills, J. W. \& 
Townes, T. M. (1982). DNA content, kinetic complexity, and the ploidy question in Candida albicans. Molecular and Cellular Biology 2, 853862.

ROEDER, G. S. (1983). Unequal crossing-over between yeast transposable elements. Molecular and General Genetics 190, 117-121.

RUBIN, G. M. (1983). Dispersed repetitive DNAs in Drosophila. In Mobile Genetic Elements, pp. 329-361. Edited by J. A. Shapiro. Orlando: Academic Press.

Scherer, S. \& Stevens, D. A. (1988). A Candida albicans dispersed, repeated gene family and its epidemiologic applications. Proceedings of the $\mathrm{Na}$ tional Academy of Sciences of the United States of America 85, 1452-1456.

Schwartz, D. C. \& CaNToR, C. R. (1982). Separation of yeast chromosome-sized DNAs by pulse field gradient gel electrophoresis. Cell 37, 67-75.

ShimidzU, K., KondoH, Y. \& TanaKa, K. (1987). Proteinase production and pathogenicity of Candida albicans. I. Invasion into chorioallantoic membrane by $C$. albicans strains of different proteinase activity. Microbiology and Immunology 31, 1045-1060.

Simon, M., Zieg, M., Silverman, M., Mandel, G. \&
Doolittle, R. (1980). Phase variation: evolution of a controlling element. Science 209, 1370-1374.

SluTsKy, V., BufFo, J. \& Soll, D. R. (1985). Highfrequency switching of colony morphology in Candida albicans. Science 230, 666-669.

Slutsky, B., Staebell, M., ANDerson, J., Risen, L., Pfaller, M. \& Soll, D. R. (1987). "White-opaque transition": a second high-frequency switching system in Candida albicans. Journal of Bacteriology 169, 189-197.

SuzUKI, S. (1981). Antigenic determinants. In Yeast Cell Envelopes: Biochemistry, Biophysics, and Ultrastructure, vol. 1, pp. 85-96. Edited by W. N. Arnold. Boca Raton, Florida: CRC Press.

Suzuki, T., Rogers, A. L. \& MAGEe, P. T. (1986a). Inter- and intra-species crosses between Candida albicans and Candida guilliermondii. Yeast 2, 53-58. Suzuki, T., Kanbe, T., Kuroiwa, T. \& Tanaka, K. $(1986 b)$. Occurrence of ploidy shift in a strain of the imperfect yeast Candida albicans. Journal of General Microbiology 132, 443-453.

Whelan, W. L. \& Magee, P. T. (1981). Natural heterozygosity in Candida albicans. Journal of Bacteriology 145, 896-903. 